\title{
Integration of organizational-technological and social aspects in the realization of the program of renovation of residential development
}

\author{
Elena Korol $^{1}$, Yuliya Gaydysheva ${ }^{1}$ and David Passmore ${ }^{2}$ \\ ${ }^{1}$ Moscow State University of Civil Engineering, Yaroslavskoe Shosse 26, Moscow, 129377, Russia \\ ${ }^{2}$ Distinguished Professor, Pennsylvania State University, University Park, PA, 16802, USA
}

\begin{abstract}
The renovation program is designed to solve a complex of problems of the city, the priority of which is a comfortable ratio of building density and developed infrastructure. The draft regional standards for urban planning has been developed for a pragmatic and at the same time comfortable layout of buildings (urban blocks) with an infrastructural core. Nevertheless, such an approach contains a number of administrative risks that can be minimized by carrying out proper planning and execution within a scheduled time frame. To improve planning accuracy, it is possible to use a system-organized block diagram consisting of integrated resettlement units. To select the optimal relocation option, it is important to carry out a multivariate analysis.
\end{abstract}

\section{Introduction}

One of the main targets which provide modern city urban policy is renovation of old buildings areas. The building density in micro districts and the choice of the areas for building are determined by the social aspects of renovation for the resettlement program and also includes organizational and technological aspects of demolition and further building. A distinctive feature of the renovation of a residential area is the provision of cyclicity and mutual coordination of the construction, resettlement and demolition processes within the same building area [1-2].

\section{Materials and methods}

Foreign experience shows that renovation programs are implemented in countries with a high level of industrialization and are regulated by a set of existing regulatory requirements, since renovation aims not only to redistribute the ratio of building density, but also to improve the quality of life of the population of megacities [1-3].

For example, in Singapore, the functional zoning of the city fits the requirements of the regulations governing the density of building. Such standards include the rationing not only of residential development, but also of access roads, landscaping, sports grounds, and even the possibility of redistributing the development intensity between neighboring quarters. In Germany, the main parameters of development are governed by territorial planning 
documents and land use plans. The options are density of the building, which are fixed for each building plan (e.g., no less than 30 thousand square meters $\mathrm{m} /$ ha for central quarter and no less than 2 thousand square meters mlha for suburban area). In Germany, there are standards for play and recreation areas, including a zone for children of all ages and a zone for children of school age [3-4].

Generally, the system of the standards and regulations in international renovation practice reflect the urban planning principles for living environment formation, which reflect the socio-economic relations. There are need to make a fund for new areas in advanced to removing citizens from old buildings which must be demolished [5].

One of peculiarities of resettlement among different districts in a megapolis is the individuality of each district, which is associated with the different number of houses to be demolished, their apartment structure, the need for resettlement, etc. Building densities of new houses also differ. As a result, a large reserve of space often is formed in a district, which allows relocation of residents from several demolished houses into one new house. In another area, there may be a shortage of areas for resettlement. So, organization of the resettlement in each district requires choosing the best option for resettlement from complex analysis tests [6-10].

Resettlement from demolished houses is carried out to pioneer buildings for the renovation area or to houses in nearby areas. And, demolished buildings make the building of the new houses possible, which is the main option of regional standards of urban planning (see Figure 1 and Figure 2).

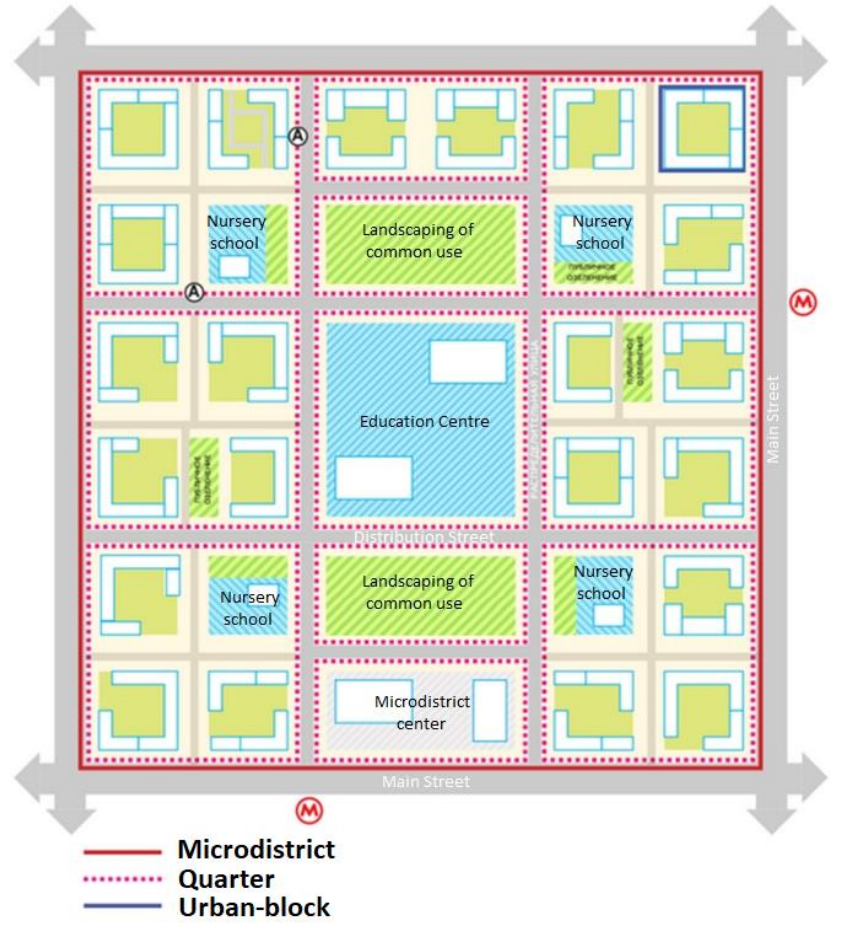

Fig. 1. Draft regional norms for urban design.

Forming a resettlement program or drawing up a resettlement schedule is a multi-step and time-consuming process. At the first stage, the address list of demolished houses is formed and analyzed, and the houses that need to be demolished first must match with planning projects and construction projects under development. The second stage 
determines the need for areas for resettlement and analyzes the possible area available for resettlement. The third and subsequent stages consider and reconcile the apartment composition, documents are prepared and documented for the resettlement of residents, resettlement is carried out, etc [7-15].

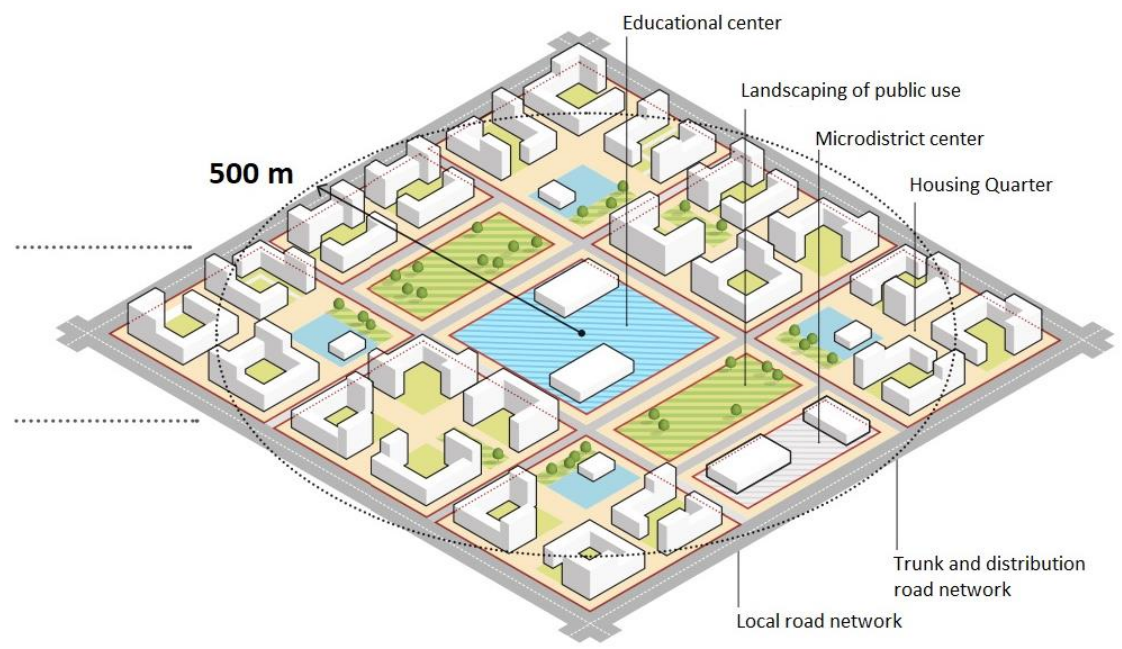

Fig. 2. More draft regional norms for urban design.

For the planning and organization of the resettlement process, it is necessary to analyze in advance the quantitative indicators, namely the need for an area for resettlement, to determine how many and which houses will need to be introduced to provide residents from demolished houses [16-18].

Usually the area available for the start-up home is adequate to relocate inhabitants from a demolished house. It often is possible to relocate residents the start-up house from several demolished houses. In other cases, options are considered with two or more start-up houses necessary to provide the required amount of resettlement, as well as more complex cases of relocation from several houses: from three or more demolished houses, in two new homes to free the site for renovation. The presented variants of resettlement organization are clearly reflected using the methods of network planning and management [9].

The process of resettlement of residents also carries administrative risks associated with the coordination of the project, documentation and other initial permits. Such risks can be divided into the following categories [20-22]:

- risks associated with the planning of the resettlement process;

- risks associated with the formulation of tasks in the technical specifications for the design of the object;

- risks associated with the coordination of resettlement and resettlement in new homes; - risks associated with insufficient planning of the flow of relocation to existing homes.

In order to minimize the occurrence of such risks, it is important to correctly plan not only the design, but also the resettlement process itself, indicating the prescribed deadlines for the execution of the assigned tasks.

This task is simplified by system-organized systems, which are based on the collection of relevant data on apartment-building, other housing parameters and the needs of immigrants. 


\section{Results}

Currently, the organization and management of renovation processes is carried out using information technology, which is a system-organized sequence of operations performed on information using tools and methods of automation (see Figure 3). One of the systemforming elements for the renovation program is the developed database "Buildings included in the program of renovation of the second wave" [10,22].

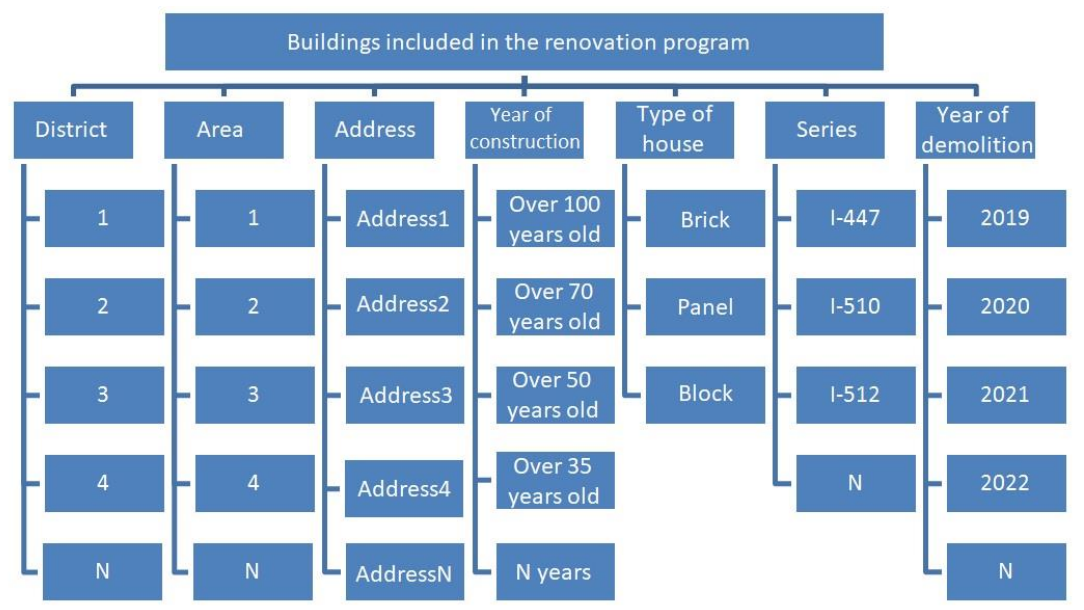

Fig. 3. Organizational structure of the database.

The database is designed to assess the physical and moral deterioration and forecast the period of dismantling of buildings. The database reflects the date of commissioning and proposed demolition, which allows to calculate the degree of wear during the start of renovation.

Shown in Figure 4 is a flowchart illustrating the resettlement process. When developing a block diagram for each area of renovation can be used as a separate sample fragments, and their different combinations depending on the characteristics of the area. This scheme highlights the main stages in the implementation of this process.

\section{Conclusions}

Organizational and technological modeling of the program of renovation of territories has the characteristic features connected with the social aspect integrated with the regulated organizational and technological processes [19].

So that that the territory released from under building can be used most rationally, design is carried out according to modern regulatory requirements in which the unit of measurement is considered to be urban-blocks, comprehensively ensuring uniform density and comfortable conditions of building.

The best option of resettlement considers the different regional characteristics selected for multivariate analysis, the intensification of which is achieved through the use of information technology, and the process of resettlement of residents of old housing in the new regulated administratively specified sequence and with a length of systematicallyorganized events. 


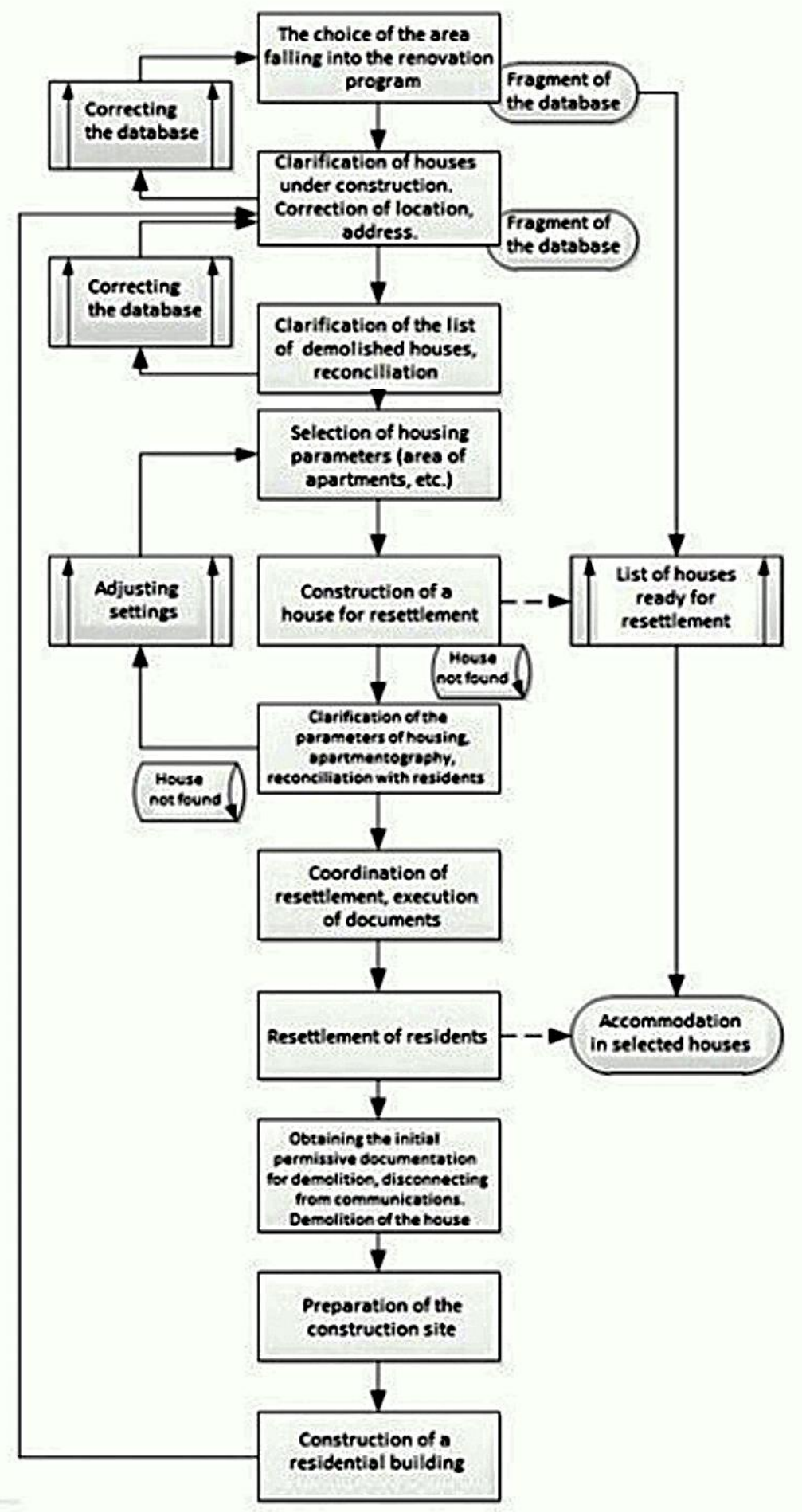

Fig. 4. Flowchart of resettlement organization. 
This work was financially supported by Ministry of Science and Higher Education of the Russian Federation (\#NSh-3492.2018.8).

\section{References}

1. Anatolevna, K. E., \& Borisovich, K. P. (2015). Management systems of urban planning. International Journal of Applied Engineering Research, 10(23), 43456-43460. Retrieved from www.scopus.com

2. Korol, E., Ostiakova, A., \& Perfilowa, E. (2018). The operational characteristics of the housing stock as a result of renovation. Paper presented at the IOP Conference Series: Materials Science and Engineering, 365(6) doi:10.1088/1757-899X/365/6/062027 Retrieved from www.scopus.com

3. Losev, K. Y., Chulkov, G. O., \& Chulkov, V. O. (2018). Comprehensive assessment of options for renovation of buildings and city blocks. Paper presented at the IOP Conference Series: Earth and Environmental Science, 177(1) doi:10.1088/17551315/177/1/012026 Retrieved from www.scopus.com

4. Booklet for the conference Of the Committee on architecture and urban planning of Moscow (moskomarchitecture) "Comfortable city". Moscow 2017.

5. Perfilova E. A., Korol E. A., Ostyakova A. V. Performance analysis updated as a result of renovation of the housing stock. In the collection: Construction-the formation of the environment XXI international scientific conference: proceedings of the seminar "youth innovation". 2018. C. 357-359.

6. Gaydysheva Y. V. Prospects for the development of a renovation program in Moscow taking into account past experience. In the collection: Technologies in engineering and ecological construction, mechanization and housing and communal complex, a collection of reports of the university scientific and technical conference. 2017. P. 160164.

7. Korol E. A. Analysis of the state and trends of urban development in the implementation of projects for the reconstruction and renovation of industrial zones in Moscow. Real estate: economics, management. 2014. № 1-2. Pp. 48-51.

8. Korol E. A., Komissarov S.V., Kagan P.B., Arutyunov S.G. Solving the problems of organizational and technological modeling of construction processes. Industrial and civil construction. 2011. № 3. P. 43-45.

9. Kievsky L. V., Kargashin M. E. Renovation by quarters (methodical issues). Residential construction. 2018. № 4. P. 15-25.

10. Kievsky L. V. Mathematical model of renovation. Residential construction. 2018. № 12. Pp. 3-7.

11. Kievsky I. L., Grishutin I. B., Kievsky L. V. The distributed reconstruction of blocks (pre-project stage). Residential construction. 2017. № 1-2. Pp. 23-28.

12. Kievsky L.V. Features of the methodology of organizing "wave" resettlement in areas of complex reconstruction. Industrial and civil construction. 2006. № 10. P. 12.

13. Database "Buildings included in the program of renovation of Moscow of the second wave" 2018.

14. Elena Korol, Vu Dinh Tho and Yuliya Kustikova Model of stressed-strained state of multi-layered reinforced concrete structure with the use of composite reinforcement. IOP Conf. Series: Materials Science and Engineering 365 (2018) 052033 doi:10.1088/1757-899X/365/5/052033

15. Borkovskaya V G 2013 The concept of innovation for sustainable development in the construction business and education. Applied Mechanics and Materials. Engineering

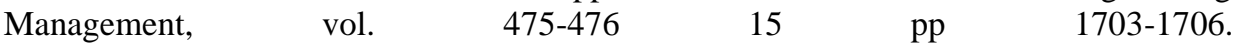
doi:10.4028/www.scientific.net/AMM.475-476.1703. 
16. Bogachev S.N., Shkolnikov A.A., Rosentul R.A., Klimova N.A. Construction risks and the possibility of minimizing them. ACADEMIA. ARCHITECTURE AND CONSTRUCTION Publisher: Russian Academy of Architecture and Construction Sciences (Moscow) ISSN: 2077-9038, Moscow, 2015 №1, p. 88-92.

17. Borkovskaya V. G. 2013 Post bifurcations of the concept of the sustainable development in construction business and education. Advanced Materials Research. Engineering Education. Vol 860-863 26 pp 3009-3012. DOI: 10.4028/www.scientific.net/AMR.860-863.3009.

18. BorkovskayaV.G., Bardenwerper W., Roe R. Interactive Teaching of Risk Management in the Russian Construction Industry. IOP Conf. Series: Materials Science and Engineering 365 (2018) 062030 doi:10.1088/1757-899X/365/6/062030

19. Borkovskaya V, Degaev E, Burkova I. Environmental economic model of risk management and costs in the framework of the quality management system // MATEC Web of Conf., 193 (2018) 05027. DOI: https://doi.org/10.1051/matecconf/201819305027.

20. Borkovskaya V, Passmore D. Application of Failure Mode and Effects Analysis in Ecology in Russia. // MATEC Web of Conf., 193 (2018) 05027. DOI: DOI: https://doi.org/10.1051/matecconf/201819305026

21. Borkovskaya V.G, Bardenwerper W, Roe R. Sustainability Risk Management: The Case for Using Interactive Methodologies for Teaching, Training and Practice in Environmental Engineering and Other Fields. Advances in Economics, Business and Management Research (France-Netherlands). Atlantis Press. In press.

22. Borkovskaya V.G., Passmore D. Behavioral engineering model to identify risks of losses in the construction industry. Advances in Economics, Business and Management Research (France-Netherlands). Atlantis Press. In press. 